Article

\title{
Research on Distribution Properties of Coating Film Thickness from Air Spraying Gun-Based on Numerical Simulation
}

\author{
Xiaopeng Xie and Yinan Wang * \\ School of Mechanical and Automotive Engineering, South China University of Technology, 381 Wushan Road, \\ Guangzhou 510641, China; xiexp@scut.edu.cn \\ * Correspondence: 201510100307@mail.scut.edu.cn
}

Received: 22 September 2019; Accepted: 24 October 2019; Published: 1 November 2019

check for updates

\begin{abstract}
This work aims to study the influence of the spraying parameters on the spray flow field and coating thickness distribution during the air spraying process. The shaping air pressure and the target geometry have an important influence on the distribution of coating film thickness. This paper begins with a 3-D physical model of an air spray gun, in which unstructured grids were generated for control domain. A grid independency study was also carried out to determine the optimal number of cells for the simulations. Then the Euler-Lagrange method was used to describe the two-phase spray flow by establishing a paint deposition model. The numerical simulation based on the discrete phase model (DPM) and TAB model has been carried out. A reasonable assumption was proposed based on the analysis of the spraying process, so that the droplets were injected into the airflow at the position of the paint hole. The influence of the shaping air pressure on the air flow field and the coating thickness distribution was analyzed by changing the shaping air pressure. From the numerical simulation results, it can be concluded that the smaller the shaping air pressure, the more concentrated the coating. With increasing the shaping air pressure, the length of the coating film along $\mathrm{z}$-axis gradually increases, the width along $\mathrm{x}$-axis gradually decreases, and the spray area gradually increases. The paper ends with a numerical simulation and experimental study on planar vertical spraying, planar tilted spraying, and cylinder spraying. Comparisons and experiment results verify the validity and practicability of the model built in this paper.
\end{abstract}

Keywords: air spraying gun; grid independency; numerical simulation; shaping air pressure; two-phase flow; coating film thickness

\section{Introduction}

Thanks to the advantages of robot spraying, such as high efficiency, better service, and protecting workers from extreme working environments, spraying robots are widely used in industries, including automobile, furniture, and spaceflight industries. Demonstration and off-line programming are two common methods used in robot spraying. Demonstration is not flexible, and the spraying quality depends more on workers' experience, while off-line programming can avoid such shortcomings. It goes like this: optimized objective function for best service quality is established according to the work-piece surface parameters and the model of coating thickness distribution and the spraying profile will be obtained through solving optimization problems [1].

Whether the model of coating thickness distribution can be calculated or not is vital for the planning of spraying profile and the improvement in spraying quality. Earlier researchers have adopted empirical formulas to simplify the spraying models, among which the infinite-range models include Cauchy distribution model [2] and Gaussian model [3], and the finite-range models which are parabolic 
distribution model [4], piecewise function distribution model [5,6], $\beta$-distribution model [7], and ellipse dual- $\beta$ distribution model [8], and so on. All of these models are based on curve fitting that is designed for specific spraying guns. Once the parameters of spraying guns change, the models will fail to work. Accordingly, the coating distribution factors cannot be wholly considered in these models, nor were the spraying process or the properties of film forming analyzed.

With the development and application of computational fluid mechanics (CFD), CFD combined with experiments is effective in the numerical simulation research on spraying processes, which can not only help analyze the film-forming mechanisms and influencing factors of spraying, but can help work out the specific distribution of spraying thickness. It is of great significance for off-line programming. The current investigations on numerical simulation of spraying are usually based on the Euler-Lagrangian method.

One method is based on experiments. In this method, it is assumed the atomization process is completed at a certain position below the nozzle, where experimental data such as droplet size and velocity distribution, gas phase velocity, and pressure should be taken $[9,10]$. The other method uses mathematical models based on atomization theory. Fogliati et al. [11] have estimated the velocity of fluid jet break-up near the nozzle through VOF. It was assumed that the initial speed of liquid drop was the same with that of jet break-up and discrete phase was set at $3.5 \mathrm{~mm}$ away from the nozzle; then coating thickness distribution was worked out from simulating calculations.

Chen et al. $[12,13]$ have established the gas-liquid flow model and turbulence model through the Euler-Euler method, in which gas and fluid drops were treated as continuous phase and calculated in the Euler coordinate system. However, this method is not suitable for sparsely distributed droplets in gas flow field, since the normal flow of coating is $300 \mathrm{~mL} / \mathrm{min}$, air flow is over $100 \mathrm{~L} / \mathrm{min}$, and volume fraction of fluid drop is less than $1 \%$.

In this paper, the DPM model and the TAB model were used for numerical simulations. The Euler-Lagrange method was used to describe the two-phase spray flow. The TAB model was used to predict the secondary breakup and the child droplets' diameters. Studies on the influence of the shaping air pressure on the air flow field and the coating thickness distribution by changing the shaping air pressure. Meanwhile, numerical simulation and experimental studies on planar vertical spraying, planar tilted spraying, and cylinder spraying were carried out. Comparisons and experiment results verified the validity and practicability of the model built in this paper.

\section{Mathematical Model}

In reality, spraying flow field can be seen as a two-phase flow of air and fluid, because the jet stream can atomize the coating into droplets, which will be sent to the target surface and form into a film. The Euler-Lagrange method was used in the modeling of the spraying process, and air was calculated in the Euler coordinate system in the form of continuous phase while droplets were calculated in the Lagrange coordinate system in the form of discrete phase. Source items of the governing equation were modified for the coupling between continuous phase and discrete phase.

The flow field of the gas phase is based on the fundamental conservation law, namely the continuity and momentum equations, which play an important role in the spray-painting process. The prediction of the flow field of the gas phase was obtained by solving the time-averaged Navier-Stokes equations and combining with the appropriate closure model for turbulence. The most commonly used model is the so-called $k-\varepsilon$, proposed by Launder and Spalding [14]. Many improvements of the $k-\varepsilon$ model have been proposed $[15,16]$. In this paper, turbulent transport was modeled using the realizable $k-\varepsilon$ model.

In the Lagrange coordinate system, droplet trajectories were calculated by integration of the equation of motion,

$$
\frac{\mathrm{d} u_{\mathrm{p}}}{\mathrm{d} t}=F_{\mathrm{D}}\left(u-u_{\mathrm{p}}\right)+F_{\mathrm{G}}
$$


in which $u$ and $u_{\mathrm{p}}$ are the velocity of gas and droplet, respectively; $F_{\mathrm{D}}\left(u-u_{\mathrm{p}}\right)$ is the drag force; $F_{\mathrm{G}}$ is the gravity force. Other forces, such as Saffman's lift and virtual mass force may be neglected, since the volume fraction of liquid is less than $1 \%$.

\section{Numerical Simulation}

\subsection{Structure of Spray Gun and Meshing}

As shown in Figure 1, the coordinate system O-XYZ was established. The origin point $\mathrm{O}$ is located at the center of the atomizing hole, the $X$ axis is parallel to the short axis of the coating, the $Y$ axis is parallel to the axis of the air spraying gun, and the $Z$ axis is parallel to the long axis.

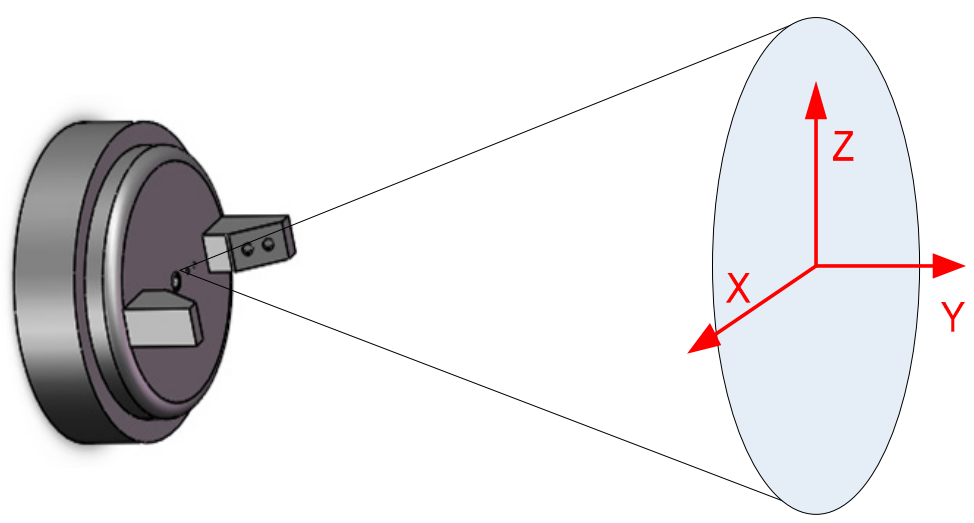

Figure 1. Schematic diagram of spray cone.

The 3-D model of air cap of air spray gun used in this paper is presented in Figure 2. It can be seen that in the model center is a round coating hole with a diameter of $1.5 \mathrm{~mm}$ and that an annular atomization hole surrounds the coating hole, from which the jet stream speeds up and helps atomize the liquid jet. On both sides of the hole there are four symmetric auxiliary atomization holes with a diameter of $0.5 \mathrm{~mm}$, which mainly help maintain a clean surface of the nozzle; on the two sides of the air cap, there are four symmetric fan control holes with a diameter of $2 \mathrm{~mm}$, which provide air flow in a certain angle to the main atomization gas flow so that the shape of spray flow field can be changed for an oval distribution of the coating.

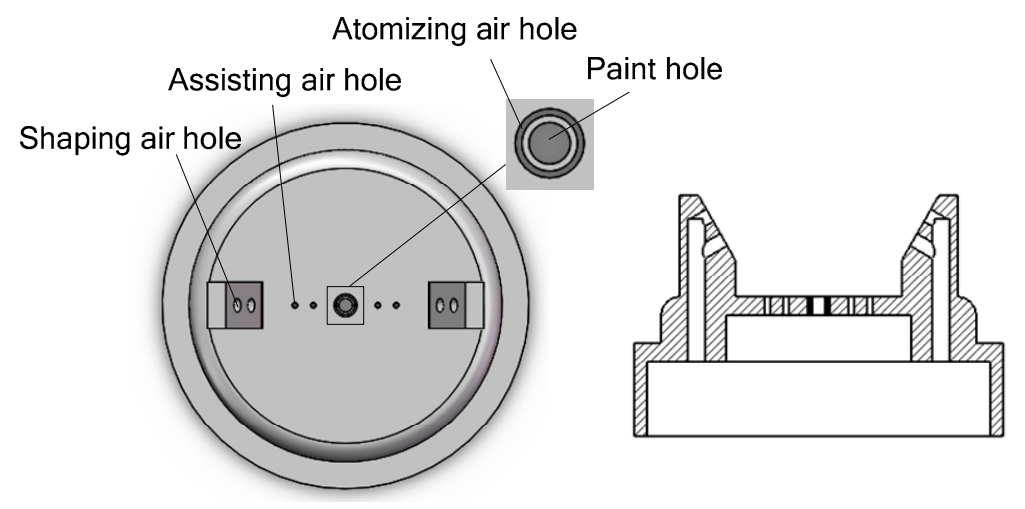

Figure 2. Geometry of the air cap.

ICEM was used for unstructured meshing, as shown in Figure 3. The air cap is located at the center of undersurface and the top surface of control domain is the target spray surface. Considering the size of the air cap and requirements of numerical simulation, the length and width of the control domain are $400 \mathrm{~mm}$ and $200 \mathrm{~mm}$, respectively, and the spray distance (distance from the paint hole to the intersection of the axis of the spraying gun and the target) is $200 \mathrm{~mm}$. To make the computation 
more accurate and to limit the total number of grids, a denser grid was used in the area around the nozzle because of the relatively small geometric construction and big gradient changes of fluid flow around the nozzle. The area far away from the nozzle uses a sparser grid.
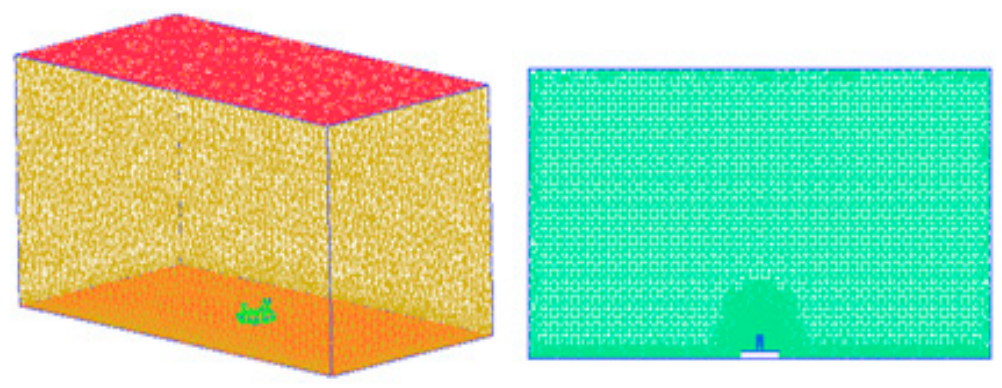

(a)
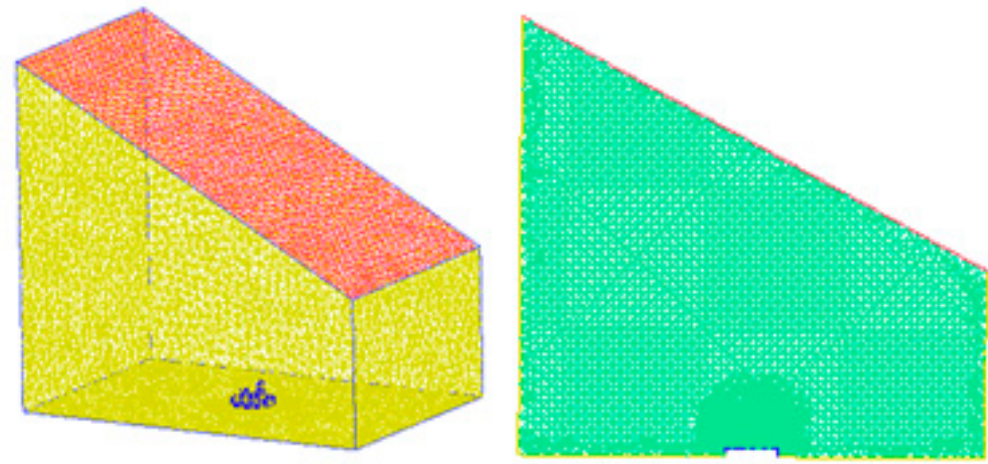

(b)

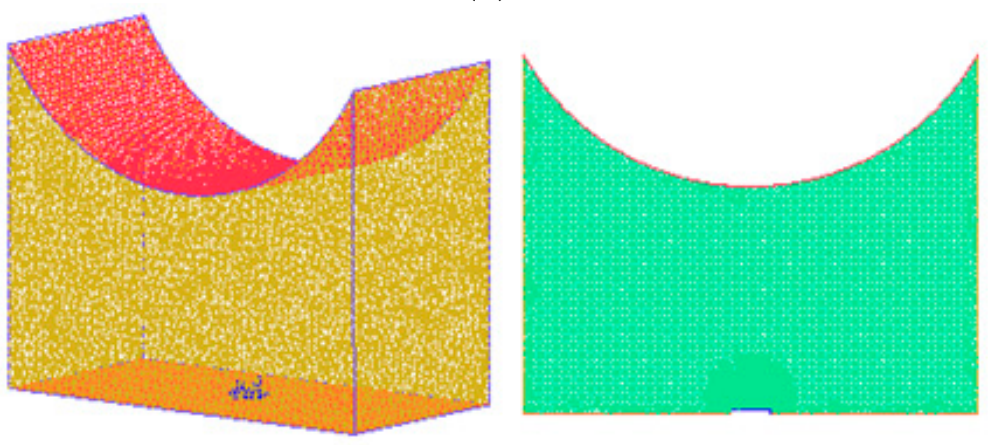

(c)

Figure 3. Mesh of air spray gun atomization flow field: (a) planar vertical spraying; (b) planar tilted spraying; (c) cylindrical spraying.

\subsection{Numerical Computation Parameters and Initial Conditions Setting}

The important parameters of the atomizer and the major properties of the materials are shown in Tables 1 and 2. The air inlet temperature is $300 \mathrm{~K}$ and the working pressure is 1 standard atmospheric pressure. The sprayed surface was set as a solid wall surface; suppose there was no heat transmission or velocity slip and the boundary condition of discrete phase was set as "trap" and the other wall surfaces were "reflect".

Table 1. Application parameters used in the simulations.

\begin{tabular}{cccc}
\hline Atomizing Air Pressure & Shaping Air Pressure & Assisting Air Pressure & Liquid Flow Rate \\
\hline $0.15 \mathrm{MPa}$ & $0,0.02,0.05,0.07 \mathrm{MPa}$ & $0.15 \mathrm{MPa}$ & $0.001 \mathrm{~kg} / \mathrm{s}$ \\
\hline
\end{tabular}


Table 2. The properties of the liquid and gas.

\begin{tabular}{cccc}
\hline Materials & Density $\mathbf{( k g / \mathbf { m } ^ { 3 } )}$ & Surface Tension $\mathbf{( m N / m )}$ & Viscosity $($ Pa.s) \\
\hline Paint & 1200 & 71.9 & 0.065 \\
Air & 1.29 & - & $1.8 \times 10^{-5}$ \\
\hline
\end{tabular}

The initial condition of discrete phase is vital to the spraying simulation. One common method goes like this: the velocity and size distribution of droplets were measured through experiments and then the discrete phase was added somewhere in the control domain to stimulate, when the fluid was assumed to be totally atomized. To make the analog computation not so dependent on experiments, the discrete phase was added at the inlet of spraying hole, so that the influence of gas flow on the movement of droplets can be taken full consideration. Spraying hole was set as the mass inlet, mass flow rate $1 \times 10^{-3} \mathrm{~kg} / \mathrm{s}$, initial velocity $5 \mathrm{~m} / \mathrm{s}$, and density $1.2 \times 10^{-3} \mathrm{~kg} / \mathrm{m}^{3}$.

Due to the complexity of liquid atomization process, the spray model established in previous studies was generally based on the assumption that the liquid instantly breaks into small droplets after leaving the nozzle. The size distribution of the droplets was obtained by experiments, which was time-consuming and expensive. Moreover, the description of droplet was not accurate, bypassing the breakup of the droplets. In this work, the Taylor analogy breakup (TAB) model [17] was used to predict the secondary breakup and the child droplets' diameters. Since the TAB model is not intended to model the primary breakup, we have to set up a model that can be used as input to the TAB model. According to reference [18], droplets with an initial diameter of $65 \mu \mathrm{m}$ were injected into the airflow at the position of the paint hole in this work. In the absence of an accurate model, this assumption is considered accurate.

In this paper, the simulation was conducted through finite volume method on a commercial software-ANSYS-Fluent 16.0. The spraying flow field can be seen as a two-phase flow of air and droplets. Since the droplets were sparse, discrete phase model was adopted in the simulation through the Euler-Lagrange method. During the modeling, air phase was treated as a continuous phase while droplets were treated as a discrete phase. Mass-momentum-heat Euler conservation equation was used in the modeling of air phase, and high-speed 3-D compressible air flow was calculated through a coupled solver. In the modeling of turbulence transmission, standard $k-\varepsilon$ model was selected. Stochastic tracking approach was used to simulate the turbulent diffusion of droplets by calculating the track of mounts of typical particles. The realizable $k-\varepsilon$ model with scalable wall function was used to model the turbulent transport. The couple solver was used to calculate the 3-D in compressible airflow. The Eulerian film model was used to calculate the coating film thickness distribution on the target.

While calculating the track of particles, the changes in heat and momentum of particles can be tracked as well. These physical quantities were used in the calculation in continuous phase to alternately solve the governing equation of discrete phase and of continuous phase until convergence appears. In this way, a dual-phase two-way coupling calculation was achieved.

\section{Results and Discussion}

\subsection{Grid Independency Study}

In the process of numerical simulation, the grid quality will affect the accuracy of calculation. Furthermore, the more cells, the longer the calculation time. In order to eliminate the influence of the number of cells on the calculation results and determine the optimal number of cells for the simulations, the study of grid independence was carried out.

In order to carry out the grid independence study, five kinds of grid were generated, with $0.2,0.5$, $0.8,1.1$, and 1.4 million cells. The atomization pressure was $0.15 \mathrm{MPa}$, and the shaping air pressure was $0.07 \mathrm{MPa}$. Figure 4 shows the effect of the number of cells on the air velocity along the air spraying gun axis. When the number of cells is small, the calculation results are related to the number of cells. When the number of cells is more than 0.8 million, the curves of air velocity along the axis 
keep the same, which indicates that the calculation results are convergent. The calculation results are independent of the number of cells. In this paper, the grid with 0.8 million cells was selected for numerical simulation.

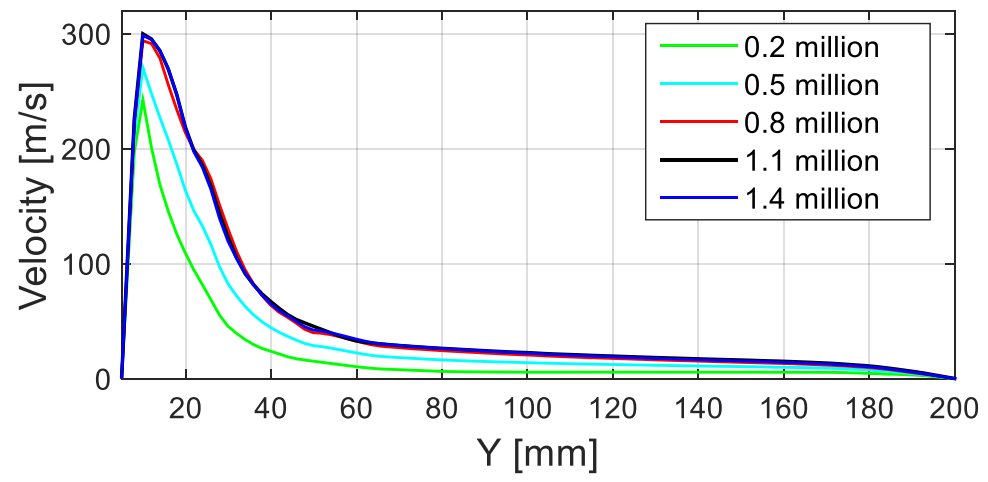

Figure 4. Comparison of air velocity along air spraying gun axis for five kinds of grids: $0.2,0.5,0.8,1.1$, 1.4 million.

\subsection{The Influence of Shaping Air Pressure on Air Flow Field}

In order to study the influence of the shaping air pressure on the airflow field, we have chosen four different shaping air pressures, respectively: 0, 0.02, 0.05, $0.07 \mathrm{MPa}$. The velocity contours along the long and short axis for four different shaping air pressures, which are shown in Figures 5 and 6. To make it easier to watch the overall flow field distribution, the maximum visual velocity was set at $50 \mathrm{~m} / \mathrm{s}$. The area near the spraying gun has higher airflow velocity. The airflow field is deformed due to the shaping air. There is a wide extension along $Z$, and a narrow extension along $X$. When the shaping air pressure is $0 \mathrm{MPa}$, the airflow field along $\mathrm{Z}$ and $X$ has the same width. With increasing shaping air pressure, the width of the airflow field along $Z$ gradually increases, and the width along $X$ gradually decreases.

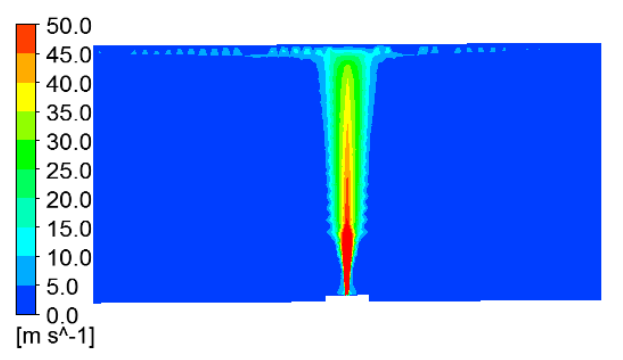

(a)

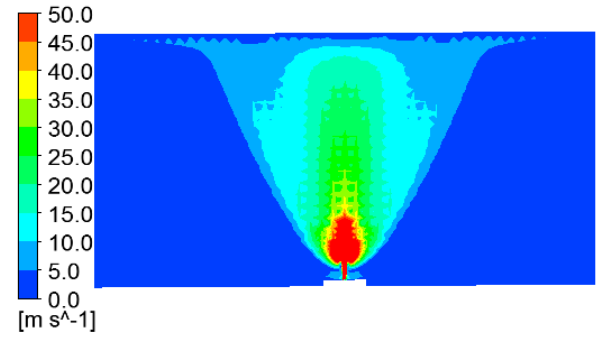

(c)

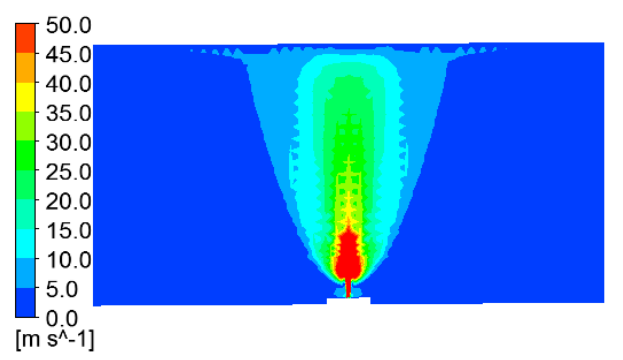

(b)

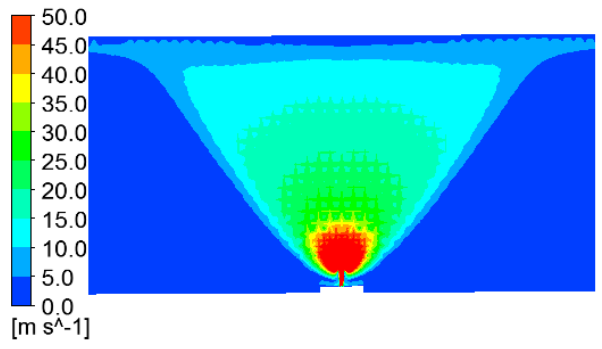

(d)

Figure 5. Velocity contours along the long axis for four shaping air pressures: (a) $0 \mathrm{MPa}$; (b) $0.02 \mathrm{MPa}$; (c) $0.05 \mathrm{MPa}$; (d) $0.07 \mathrm{MPa}$. 


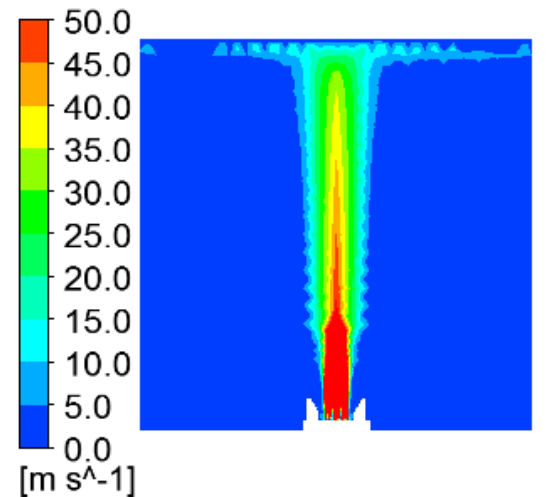

(a)

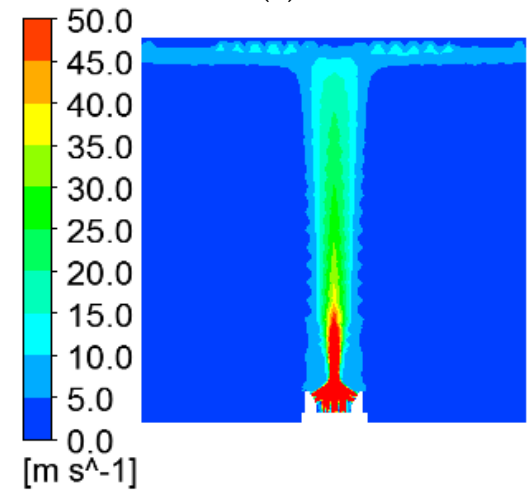

(c)

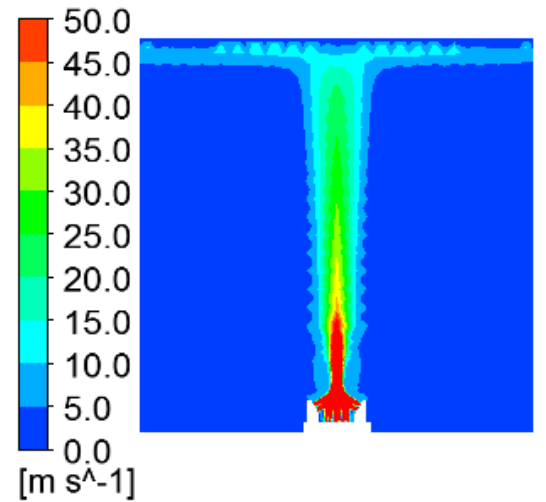

(b)

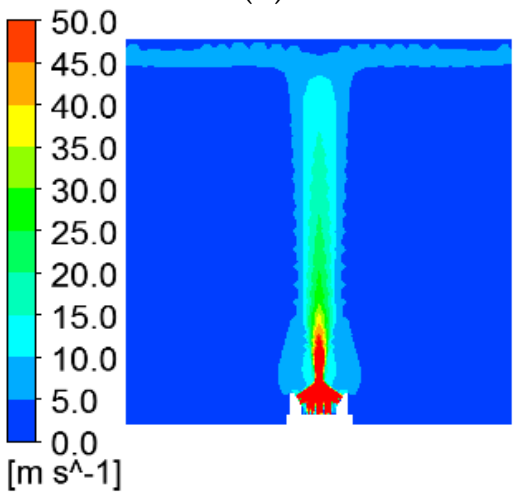

(d)

Figure 6. Velocity contours along the short axis for four shaping air pressures: (a) $0 \mathrm{MPa}$; (b) $0.02 \mathrm{MPa}$; (c) $0.05 \mathrm{MPa}$; (d) 0.07 MPa.

\subsection{The Influence of Shaping Air Pressure on Coating Film Thickness Distribution}

The coating film thickness distribution contours under different shaping pressure are shown in Figure 7. The dependency of the coating film thickness on the shaping air pressure is shown in Figure 8 and Table 3. The liquid paint is transported to the plate under the action of airflow. The coating film thickness distribution is greatly influenced by the shaping air. When the shaping air pressure is $0 \mathrm{MPa}$, the coating film is round in shape. The length of both the long and short axis was $78 \mathrm{~mm}$, and the area of the coating film was about $4775.94 \mathrm{~mm}^{2}$. The liquid paint was concentrated in the center of the plate. With increasing shaping air pressure, the length of the long axis of the coating film gradually increased, and the length of the short axis gradually decreased. The coating film thickness at the center of the plate decreased gradually, and the area of the coating film increased gradually. When the shaping air pressure is $0.07 \mathrm{MPa}$, a quite narrow elliptic coating film was formed with a narrow extension along $\mathrm{X}$. The length of the long axis was $286 \mathrm{~mm}$, and the short axis was $51 \mathrm{~mm}$. The area of the coating film was $11450.01 \mathrm{~mm}^{2}$.

Table 3. Coating film thickness distribution for four shaping air pressures.

\begin{tabular}{cccc}
\hline $\begin{array}{c}\text { Shaping Air } \\
\text { Pressure/MPa }\end{array}$ & $\begin{array}{c}\text { Length of Long } \\
\text { Axis/mm }\end{array}$ & $\begin{array}{c}\text { Length of Short } \\
\text { Axis/mm }\end{array}$ & $\begin{array}{c}\text { Area of Coating } \\
\text { Film/mm } \mathbf{~}^{\mathbf{m}}\end{array}$ \\
\hline 0 & 78 & 78 & 4775.94 \\
0.02 & 172 & 64 & 8641.28 \\
0.05 & 235 & 55 & 10146.13 \\
0.07 & 286 & 51 & 11450.01 \\
\hline
\end{tabular}




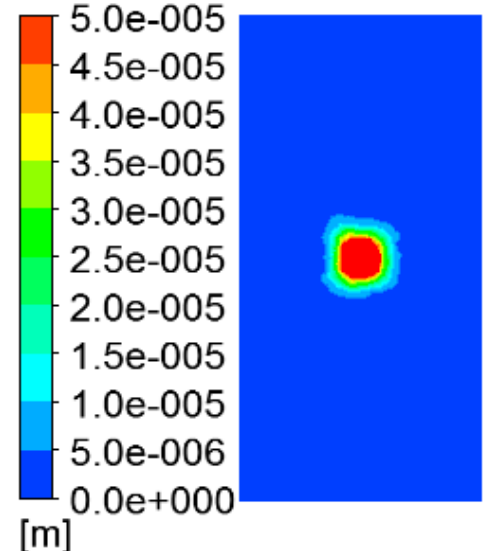

(a)

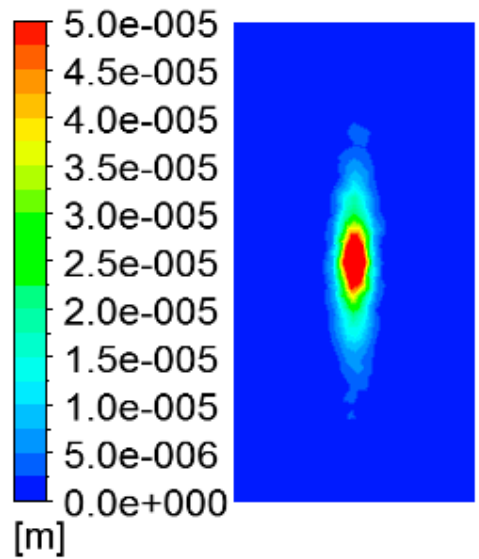

(c)

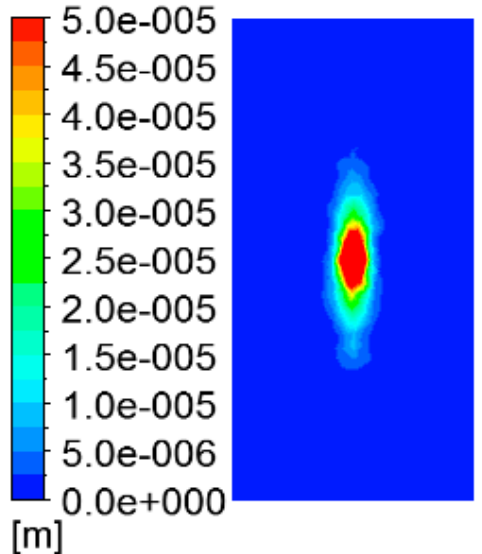

(b)

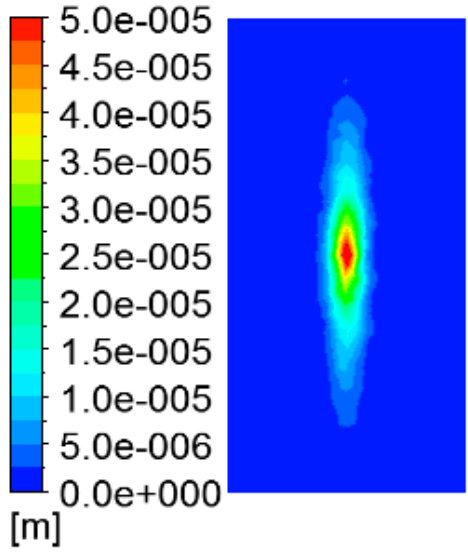

(d)

Figure 7. Coating film thickness distribution contours for four shaping air pressures: (a) $0 \mathrm{MPa}$; (b) $0.02 \mathrm{MPa}$; (c) $0.05 \mathrm{MPa}$; (d) $0.07 \mathrm{MPa}$.

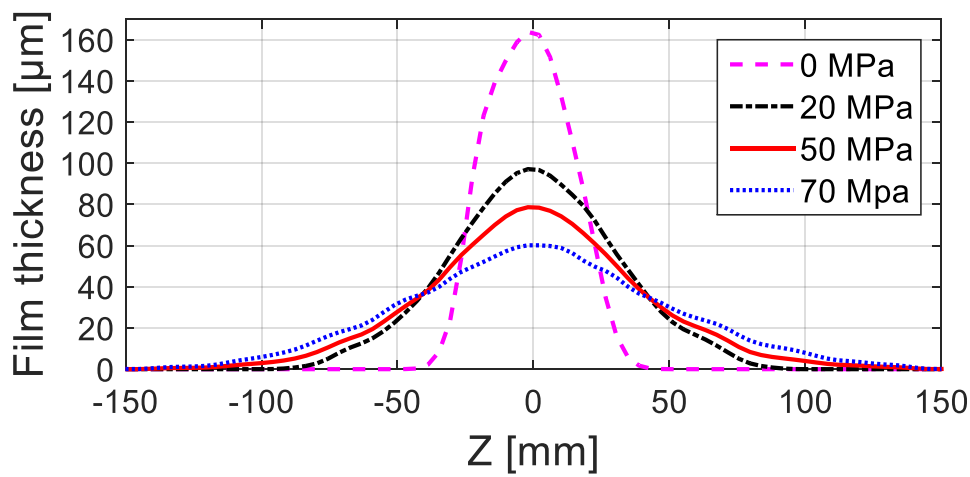

Figure 8. Comparison of coating film thickness distribution along $\mathrm{Z}$ for four shaping air pressures: 0 , $0.02,0.05,0.07 \mathrm{MPa}$.

\section{Experimental Investigation}

To verify the simulation results, an air spraying experiment was conducted. The spraying robot used in this paper is shown in Figure 9, and the coating thickness gauge is shown in Figure 10. The spraying reached as high as $200 \mathrm{~mm}$ and lasted for $1 \mathrm{~s}$, which was measured through a stopwatch. After the coating film was solidified, its thickness was measured through a coating thickness gauge along the long axis at an interval of $10 \mathrm{~mm}$. At each point, the thickness was measured five times and the average value was seen as the thickness, which was divided by five. The final value is the thickness 
at the time of $0.2 \mathrm{~s}$. The thickness from analog simulation was that of wet coating film, which should be transformed into that of dry coating film through the following equation:

$$
h_{2}=h_{1} \times V_{\mathrm{s}}
$$

where $h_{1}$ is the thickness of wet coating film; $h_{2}$ is the thickness of dry coating film, and $V_{\mathrm{s}}$ is the content of solid in paint volume.

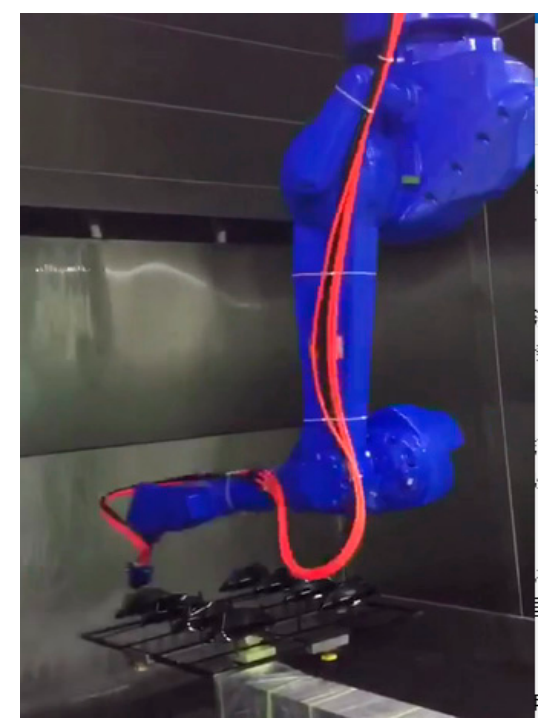

Figure 9. Spraying robot.

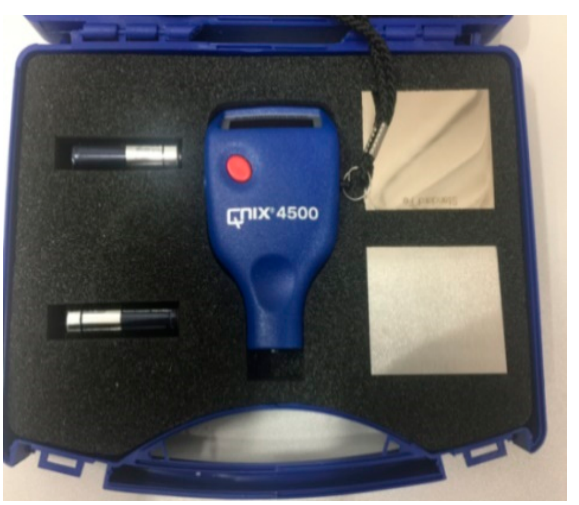

Figure 10. Coating thickness gauge.

The measurement uncertainty of the coating film thickness was analyzed by solving the sample standard deviation. The sample standard deviation of each measurement point can be expressed as Equation (3).

$$
s=\sqrt{\frac{\sum_{i=1}^{n}\left(x_{i}-\bar{x}\right)}{n-1}}
$$

where $x_{i}$ is the thickness of each measurement, $\bar{x}$ is the mean value of $n$ measurements. $n$ is the number of repeated measurements at each point.

\subsection{Planar Vertical Spraying}

In order to verify the applicability of the numerical method, additional tests were carried out by purposefully increasing the complexity of the target geometry. The plane vertical spraying is shown in 
Figure 11. The shaping air pressure is $0.07 \mathrm{MPa}$. Figure 12 shows the comparison of experimental and simulated coating film. The shape and size of the coating film of the experiment is quite similar to that of numerical simulation: the coating film is a narrow oval in shape. Figure 13 shows the comparison of experimental and simulated coating film thickness distribution in the plane $X=0$. It can be seen that the simulated and experimental results are in good agreement. Figure 14 shows the sample standard deviation of each measurement point. The standard deviation at the middle position is larger, and gradually decreases towards both sides. The maximum value of the standard deviation is $0.22 \mu \mathrm{m}$. It indicates that the measurement results are reliable.

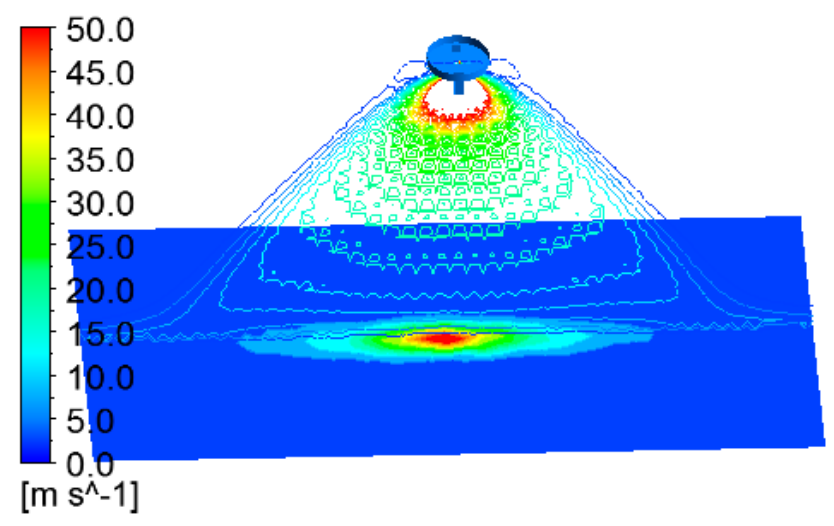

Figure 11. Plane vertical spraying: velocity contours in the plane $X=0$ overlaid with static coating film thickness on the target.

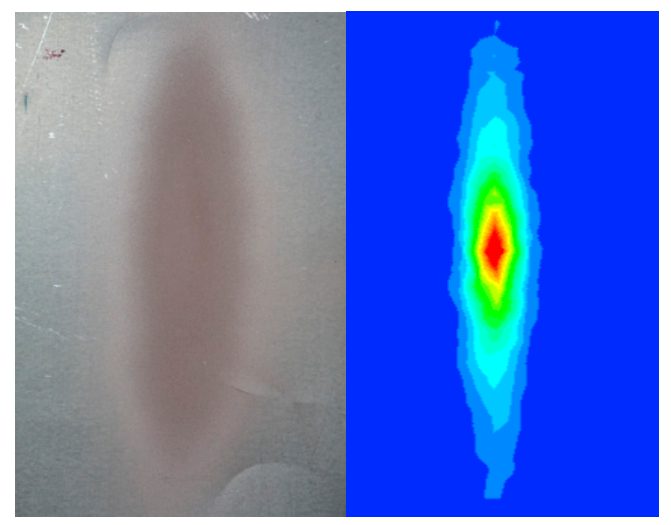

Figure 12. Comparison of experimental and simulated coating film.

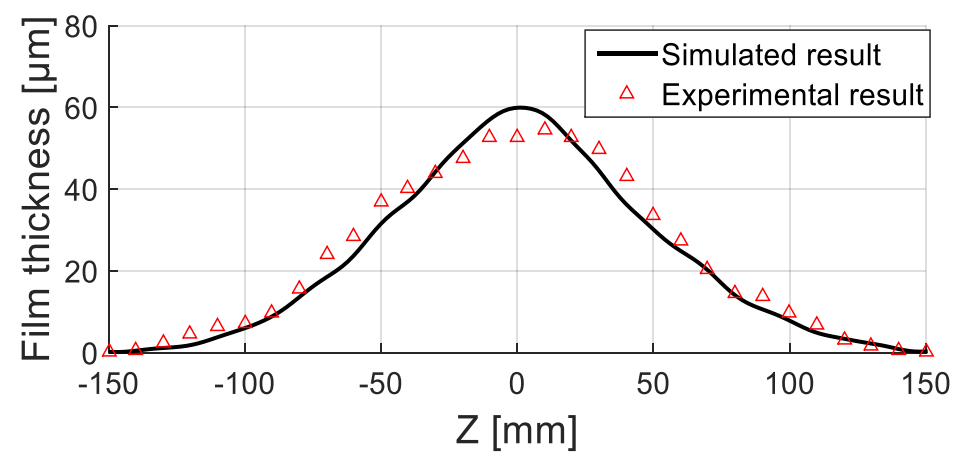

Figure 13. Plane vertical spraying: comparison of experimental and simulated coating film thickness distribution in the plane $X=0$. 


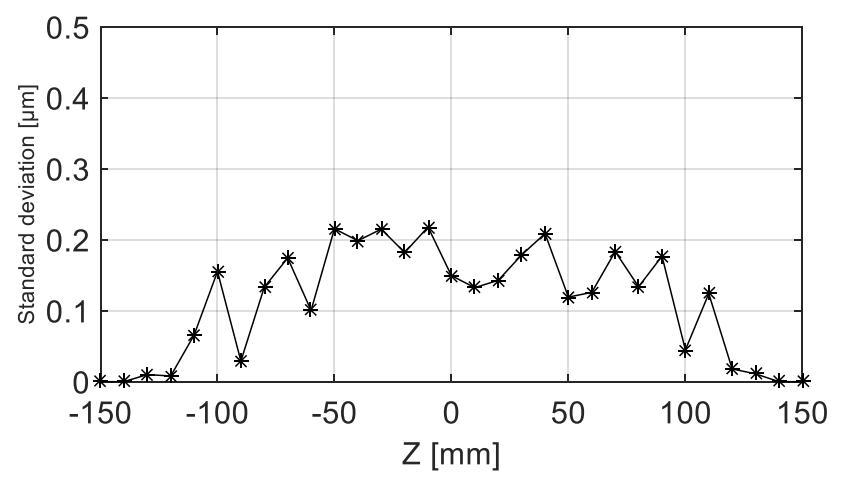

Figure 14. Plane vertical spraying: sample standard deviation of each measurement point.

\subsection{Planar Tilted Spraying}

In reality, the shape of the target is usually complicated, so the spraying gun cannot be always vertical to the target surface and the target surface is not always a plane. Therefore, plane tilted spraying and cylindrical spraying were taken into consideration in this paper. In planar tilted spraying, the spraying gun is $60^{\circ}$ to the target surface, which is shown in Figure 15. Parameter settings are the same with those in planar vertical spraying. The coating film from the experiment is basically identical to that from the simulation in terms of shape and size. The length of the coating film is longer on the side far away from the spraying gun than the other, as is displayed in Figure 16. The comparison of experimental and simulated coating film thickness distribution in the plane $X=0$ is shown in Figure 17, which reveals that the experimental results are in agreement with the simulated result. Figure 18 shows the sample standard deviation of each measurement point. The maximum value of the standard deviation is $0.24 \mu \mathrm{m}$. It indicates that the measurement results are reliable.

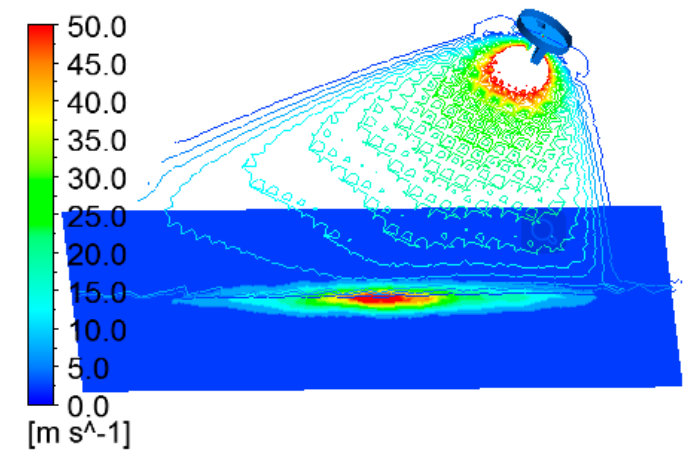

Figure 15. Planar tilted spraying: velocity contours in the plane $X=0$ overlaid with static coating film thickness on the target.

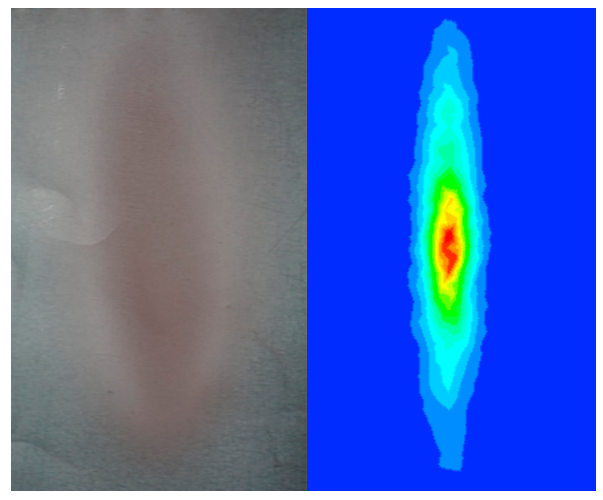

Figure 16. Planar tilted spraying: comparison of experimental and simulated coating film. 


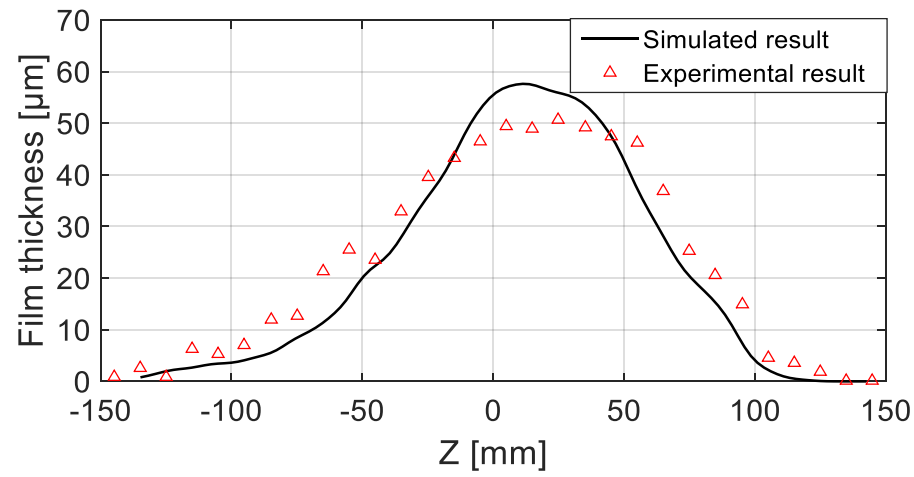

Figure 17. Planar tilted spraying: comparison of experimental and simulated coating film thickness distribution in the plane $X=0$.

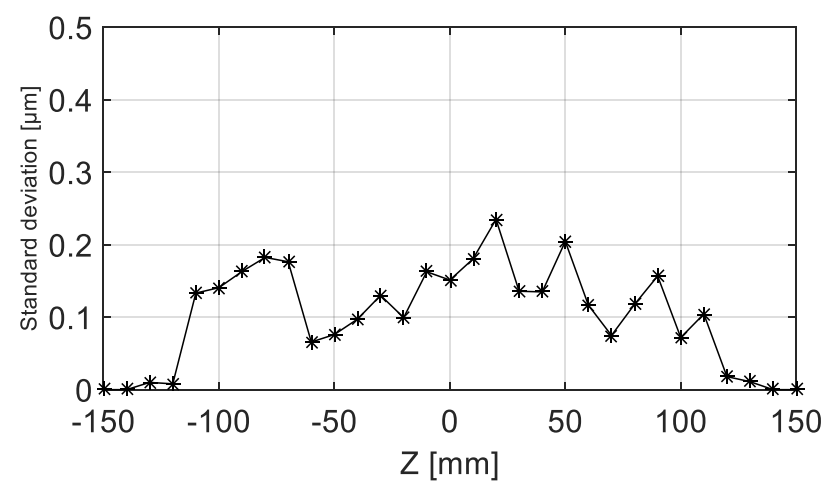

Figure 18. Planar tilted spraying: sample standard deviation of each measurement point.

\subsection{Cylindrical Spraying}

In cylindrical spraying, the target surface is an arc surface with a diameter of $400 \mathrm{~mm}$, which is shown in Figure 19. The parameter settings are the same with those in planar vertical spraying. The coating film from the experiment and that from simulation are basically the same in terms of shape and size: an oval shape, just as is displayed in Figure 20. Due to the convex surface, the length of long axis of coating film is longer than planar vertical spraying, and the film thickness is smaller. Figure 21 shows the comparison of experimental and simulated coating film thickness distribution in the plane $X=0$. It can be seen that the simulated and experiment results are in good agreement. Figure 22 shows the sample standard deviation of each measurement point. The maximum value of the standard deviation is $0.25 \mu \mathrm{m}$. It indicates that the measurement results are reliable.

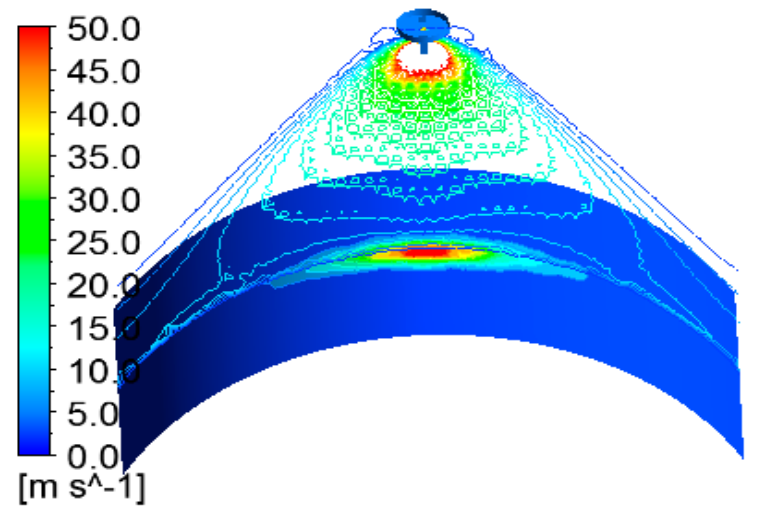

Figure 19. Cylindrical spraying: velocity contours in the plane $X=0$ overlaid with static coating film thickness on the target. 


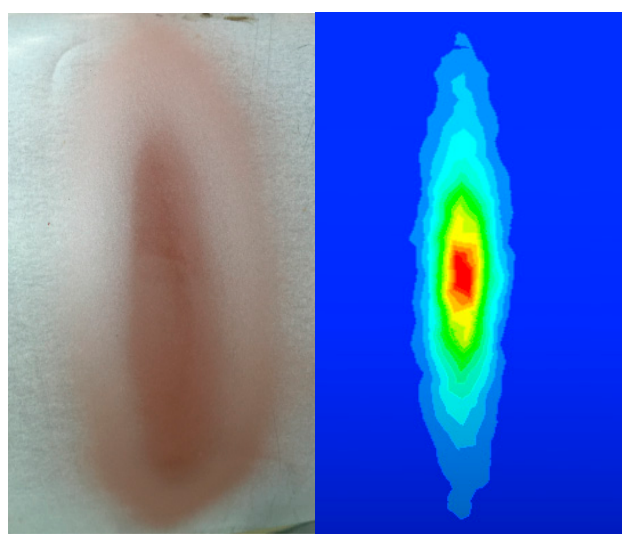

Figure 20. Cylindrical spraying: comparison of experimental and simulated coating film.

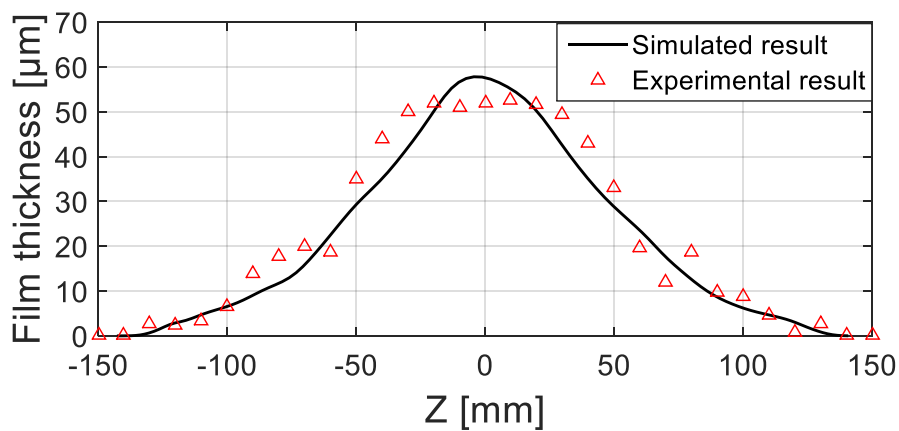

Figure 21. Cylindrical spraying: comparison of experimental and simulated coating film thickness distribution in the plane $X=0$.

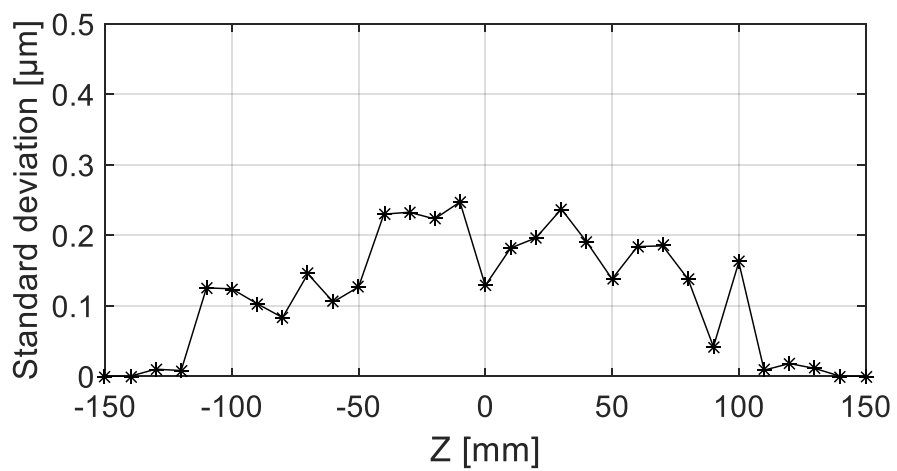

Figure 22. Cylindrical spraying: sample standard deviation of each measurement point.

\section{Conclusions}

First of all, in this paper, a 3-D physical model of an air spraying gun was established. Unstructured grids were generated for control domain. A grid independency study was also carried out. When the number of cells is small, the calculation results are related to the number of cells. When the number of cells is not less than 0.8 million, the curves of air velocity along the axis stay the same, which indicates that the calculation results are convergent and independent of the number of cells. Therefore, the grid with 0.8 million cells was selected for numerical simulation in this paper.

Secondly, numerical simulation based on the TAB model and the DPM model was carried out to describe the two-phase flow field. The TAB model was used to predict the secondary breakup and the child droplets' diameters. The DPM model was used to calculate the droplets' trajectories. The shaping air has great influence on the airflow field and the coating film thickness distribution. The smaller the shaping air pressure, the more concentrated the coating at the center of target, which easily leads to 
overspraying. With increasing shaping air pressure, the length of the airflow field and coating film along the Z-axis gradually increases, and the width along gradually decreases, and the area of the coating film gradually increases. So, the spraying guns that have large shaping air pressure could obtain higher spraying efficiency and better spraying quality. However, if the shaping air pressure is too large, it may result in lower paint utilization. When the shaping air pressure is $0 \mathrm{MPa}$, the airflow field along $Z$ and $X$ has the same width, the coating film is round in shape, both the length of the coating film along $Z$-axis and the width along $X$-axis are $78 \mathrm{~mm}$, and the area of the coating film is about $4775.94 \mathrm{~mm}^{2}$. When the shaping air pressure is $0.07 \mathrm{MPa}$, a quite narrow elliptic coating film is formed with a narrow extension along $X$-axis, the length of the coating film along Z-axis is $286 \mathrm{~mm}$, the width along $X$-axis is $51 \mathrm{~mm}$, and the area of the coating film is $11450.01 \mathrm{~mm}^{2}$.

Lastly, experiments and numerical simulations were carried out for planar vertical spraying, planar tilted spraying, and cylindrical spraying, respectively. The coating film of simulation and experiment are almost the same in shape and size; besides, the coating film thickness distribution of simulations and experiments are in good agreement. All these indicate that the numerical simulation method used in this paper is feasible and applicable for a complicated target.

Author Contributions: Conceptualization, X.X.; Numerical Simulations, Y.W.; Writing-Original Draft Preparation, Y.W.

Funding: This research received no external funding.

Conflicts of Interest: The authors declare no conflict of interest.

\section{References}

1. Andulkar, M.V.; Chiddarwar, S.S.; Marathe, A.S. Novel integrated offline trajectory generation approach for robot assisted spray painting operation. J. Manuf. Syst. 2015, 37, 201-216. [CrossRef]

2. Antonio, J.K. Optimal trajectory planning for spray coating. In Proceedings of the 1994 IEEE International Conference on Robotics and Automation, San Diego, CA, USA, 8-13 May 1994; pp. 2570-2577. [CrossRef]

3. Freund, E.; Rokossa, D.; Rossmann, J. Process-oriented approach to an efficient off-line programming of industrial robots. In Proceedings of the Iecon 98 24th Annual Conference of the IEEE Industrial Electronics Society, Aachen, Germany, 31 August-4 September 1998; IEEE: New York, NY, USA, 1998; Volume 1-4, pp. 208-213.

4. Chen, H.P.; Xi, N.; Sheng, W.H.; Chen, M.F. General framework of optimal tool trajectory planning for free-form surfaces in surface manufacturing. J. Manuf. Sci. Eng. Trans. ASME 2005, 127, 49-59. [CrossRef]

5. Klein, A. CAD-based off-line programming of painting robots. Robotica 1987, 5, 267-271. [CrossRef]

6. Feng, C.; Sun, Z.-Q. Models of spray gun and simulation in robotics spray painting. Robot 2003, 25, 353-358.

7. Arikan, M.A.S.; Balkan, T. Modeling of paint flow rate flux for elliptical paint sprays by using experimental paint thickness distributions. Ind. Robot 2006, 33, 60-66. [CrossRef]

8. Zhang, Y.; Huang, Y.; Gao, F.; Wang, W. New model for air spray gun of robotic spray-painting. Chin. J. Mech. Eng. 2006, 42, 226-233. [CrossRef]

9. Lindenthal, A.; Domnick, J.; Tropea, C.; Xu, T.-H. Application of phase doppler anemometry in paint sprays. At. Sprays 1994, 4, 437-450. [CrossRef]

10. Ye, Q.Y.; Pulli, K. Numerical and experimental investigation on the spray coating process using a pneumatic atomizer: Influences of operating conditions and target geometries. Coatings 2017, 7, 10. [CrossRef]

11. Fogliati, M.; Fontana, D.; Garbero, M.; Vanni, M.; Baldi, G.; Donde, R. CFD simulation of paint deposition in an air spray process. JCT Res. 2006, 3, 117-125. [CrossRef]

12. Chen, Y.; He, S.; Zhang, G.; Chen, W. Two-fluid model simulation of paint deposition on flat wall in an air spray process. J. Logist. Eng. Univ. 2015, 31, 82-86.

13. Chen, Y.; Chen, W.Z.; He, S.W.; Pan, H.W.; Li, B.; Zhang, W.M. Spray flow characteristics of painting cylindrical surface with a pneumatic atomizer. China Surf. Eng. 2017, 30, 122-131.

14. Launder, B.E.; Spalding, D.B. The numerical computation of turbulent flows. Comput. Methods Appl. Mech. Eng. 1974, 3, 269-289. [CrossRef] 
15. Shih, T.H.; Liou, W.W.; Shabbir, A.; Zhigang, Y.; Jiang, Z. A new k-epsilon eddy viscosity model for high Reynolds number turbulent flows. Comput. Fluids 1995, 24, 227-238.

16. Yakhot, V.; Orszag, S.A. Renormalization-group analysis of turbulence. Phys. Rev. Lett. 1986, 57, $1722-1724$. [CrossRef] [PubMed]

17. O'Rourke, P.J.; Amsden, A.A. The tab method for numerical calculation of spray droplet breakup. In Proceedings of the International Fuels and Lubricants Meeting and Exposition, Toronto, ON, Canada, 2-5 November 1987.

18. Li, W.T.; Qian, L.J.; Song, S.B.; Zhong, X.K. Numerical study on the influence of shaping air holes on atomization performance in pneumatic atomizers. Coatings 2019, 9, 15. [CrossRef]

(C) 2019 by the authors. Licensee MDPI, Basel, Switzerland. This article is an open access article distributed under the terms and conditions of the Creative Commons Attribution (CC BY) license (http://creativecommons.org/licenses/by/4.0/). 